\title{
La importancia del tratamiento de la religión en medios de comunicación. El caso del Islam en España
}

\author{
Pilar SÁNCHEZ GONZÁLEZ \\ ESIC Business \& Marketing School \\ pilar.sanchez@esic.edu \\ Graciela Padilla Castillo \\ Universidad Complutense de Madrid \\ gracielapadilla@ccinf.ucm.es
}

Recibido: $29 / 11 / 2012$

Aceptado: 23/01/2013

\section{Resumen}

El objetivo de este artículo es analizar la relación entre medios de comunicación y religiones mayoritarias, que se practican en España y, en concreto, el Islam. Como objetivo secundario, se pretende abrir nuevas líneas de investigación y remarcar la importancia del asunto. La información es un servicio de socialización. Por ello, se deben respetar las diferencias políticas, ideológicas, sociales y culturales. En el caso del entorno cultural, la religión es una de las variables a considerar en la práctica de la correcta información, evitando clichés y acciones no respetuosas hacia algunos de sus fieles. Si se quiere ser objetivo, hay que ser respetuoso. Conocer las religiones que se practican en el país supone una mejor adecuación en el tratamiento de la información. Los medios son transmisores de valores y estos, a su vez, socializadores de la audiencia.

Palabras clave: Medios de comunicación, Religión, Islam, Ética sobre información religiosa.

\section{The Importance of Religion Treatment in the Media. The Case of Islam in Spain}

\begin{abstract}
The objective of this paper is to analyze the relationship between the media and major religions, practiced in Spain and, in particular, Islam. As a secondary objective, is to open new lines of research and highlight the importance of the matter. The information is socialization service. Therefore, we must respect the political, ideological, social and cultural differences. In the case of the cultural environment, religion is one of the variables to consider in the practice of correct information, avoiding clichés and not respectful actions towards some of its faithful followers. If you want to be objective, you have to be respectful. Knowing the religions practiced in the country is a better fit in the information processing. The media are transmitters of values and these, in turn, socialize the audience.
\end{abstract}

Keywords: Media, Religion, Islam, Ethics on religious information.

\section{Referencia normalizada}

SÁNCHEZ GONZÁLEZ, Pilar y PADILLA CASTILLO, Graciela (2013): "La importancia del tratamiento de la religión en medios de comunicación. El caso del Islam en España”. Estudios sobre el Mensaje Periodístico. Vol. 19, Núm. especial marzo, págs.: 449-457. Madrid, Servicio de Publicaciones de la Universidad Complutense.

Sumario: 1. Introducción. 2. Metodología. 3. Desarrollo. 4. Conclusiones. 5. Referencias bibliográficas

\section{Introducción}

A la hora de abordar el fenómeno de la religión en los medios de comunicación, se puede destacar que la frontera entre la información y el espectáculo es cada vez más difusa. Hay un predominio de la industria del entretenimiento sobre el de la información. 
Conviene recordar que la sociedad del ocio, con más tiempo libre y menos tiempo para el trabajo, no es novedosa. Los antiguos romanos ya dividían el tiempo en ocio (otium) y negocio (no-cio, nec-otium). Hoy, como entonces, los agentes de socialización, familia y escuela, tienen que compartir esta función con los medios de comunicación. Muy especialmente, con la televisión e Internet, en el caso de los niños y jóvenes. De ahí la enorme responsabilidad de los profesionales y medios de comunicación, en la elección de los contenidos de las programaciones. Muchos de los valores que se consideraban intrínsecos a los profesionales de la comunicación se han perdido en favor de una mercantilización de la profesión.

Queremos recordar que la información es, también, un servicio de socialización. Por ello, se deberían respetar las diferencias políticas, ideológicas, sociales y culturales. En el caso del entorno cultural, la religión es una de las variables a considerar en la práctica de la correcta información, evitando clichés y acciones no respetuosas hacia algunos de sus fieles. Si se quiere ser objetivo, hay que ser respetuoso. Conocer las religiones que se practican en el país supone una mejor adecuación en el tratamiento de la información. Los medios son transmisores de valores y estos, a su vez, socializadores de la audiencia.

La religión desempeña un papel muy importante en la cultura de la humanidad. Cultura y religión se influyen mutuamente. La religión da forma a los sistemas de creencias y prácticas que se inscriben en la cultura particular que le corresponda. La misma cultura, por su parte, influye sobre los modos de prácticas, la integración religiosa y las creencias necesarias para llevar a cabo sus rituales en la vida social. No hay cultura que actúe ajena a una religión, sea de forma directa o indirecta. Y no hay cultura desarrollada sin el adecuado entendimiento de su religión (Parekh, 2005).

La religión, en sí misma, pretende aunar la realidad de la humanidad con la realidad universal. Por tanto, la profesión de unas creencias religiosas sirve para legitimar y conservar la realidad de una sociedad. Se convierte en catalizador y herramienta de transformación de la propia cultura de la sociedad que acoge, pudiendo contribuir a la cohesión del conjunto de la sociedad (Garreta, 2003). De hecho, la sociedad, la religión y su cultura están estrechamente interrelacionadas.

Desde esta perspectiva, el Islam tiene un papel fundamental en la cultura de la comunidad islámica, ya que las personas que la profesan consideran la religión como elemento esencial. Creen que dicha religión y sus creencias son elementos que les ayudan a conservar su propia cultura (Sánchez, 2012: 22). Su evolución depende de cómo se interrelacionen los elementos que la componen: idiomas, costumbres o expresiones artísticas y, por otro lado, de cómo se interpreten los textos que siguen.

Tal como sostienen los islamólogos Mohamed Bahige Mullá y Abdelouahab Atta, el Islam consta de tres elementos: Fe y culto, Derecho (Sharia) y Mensaje. Fe y culto son particularidades personales que ocupan el espacio más restringido. El culto mismo se divide en culto a Dios en reconocimiento a Su Unicidad (oraciones y peregrinación) y culto a Dios (Ortopraxia), que es todo acto cívico realizado al servicio de la sociedad para agradar a Dios. El Islam es, ante todo, una religión social cuyo objetivo primordial es preparar al ser humano para desenvolverse sanamente en la vida de este mundo. 
El Derecho o Sharia es el conjunto de disposiciones legales; muy parecidas a lo que llamamos ley marco y por tanto, abierto a incluir innovaciones contextuales de tipo legislativo que regulan la vida pública. Siempre y cuando no violen la base y el espíritu del Islam. A nivel colectivo, tiene valor normativo sólo en un país que la adopte como ley vigente y, por lo tanto, no nos concierne en España. La Sharia "tiene como particularidad el saber adaptarse a distintas situaciones gracias a la ausencia de una autoridad única que controla la ortodoxia" (Necco, 2010).

El Mensaje es el tercer elemento básico. El conjunto de valores normativos que no difieren mucho de la escala de valores universales y que tiende a establecer una base sólida para el desarrollo de la sociedad humana. El Mensaje islámico inculca que:

- La variedad de credos es una voluntad divina (Corán 10/99 y 18/29) y en consecuencia, la compulsión en materia de fe es un delito (pecado) mayor.

- La libertad de creer y de expresar la cultura religiosa es un valor moral y un derecho inalienable y, en virtud de este valor, los lugares de culto, los clérigos y el patrimonio religioso gozan de inmunidad legal.

- El desprecio dirigido contra los símbolos de cualquier religión (blasfemia) es un delito punible (Corán 6/106-108).

- Conocer al "diferente" es un deber cívico, porque el "diferente" es el prójimo que siempre tendrá algo que comunicar y para conocerle bien hay que seguir la vía del diálogo y de la dialéctica (Corán 49/13 y 34/24)

- La construcción social es el campo donde tenemos que competir y concurrir, de tal manera que la personalidad social del individuo se consolide con la personalidad moral (Corán 2/48)

- La convivencia intercomunitaria es una necesidad para el desarrollo social integral. Todos los seres humanos son miembros de una sola familia universal, el más apreciado por Dios de entre ellos es el que mejor sirve a la Familia.

- Por tanto, el objetivo del Islam es dotar a sus creyentes de la herramienta necesaria para que goce de una vida sana en consonancia con el ecosistema en el que habite.

Después de acercarnos, breve y humildemente, a los principios del Islam, abordamos el estado de la cuestión y por qué Islam y medios de comunicación son una importante vía de investigación. Bensalah (2006: 70-71) explica cómo los medios de comunicación han sido precursores de una nebulosa islamista, un Islam terrógeno y cierta islamofobia tras los atentados del 11-S: "Desde las ruinas humeantes de las Torres Gemelas y del Pentágono, George W. Bush desveló claramente sus intenciones hacia todos los musulmanes del mundo, cargadas de suposiciones y de retórica guerrera, que no dejan entrever ninguna duda sobre su visión dicotómica del mundo. Hablando unas veces de cruzadas, de choques de civilizaciones, y otras del Imperio del mal, no dudaba en amalgamar mediante una semántica dudosa, Islam, islamismo rigorista y reivindicaciones guerreras en el nombre de Alá" (Bensalah, 2006: 70-71).

El mismo autor se refiere a las noticias sobre el velo islámico, "utilizando los mismos clichés, hace renacer las mismas incomprensiones además de generar xenofobia y racismo. La crispación en torno al velo, calificado de islámico, y los debates sobremediatizados e instrumentalizados políticamente son tristes ejemplos de ello. Anali- 
zando y examinando el tema del velo, la televisión proyecta sus propios miedos imponiendo un cuadro de lectura maniquea" (Bensalah, 2006: 72).

Saini (2009: 1-17) dedica un texto completo a distinguir entre Al Qaida e Islamismo. Según la autora: "En el marco de las relaciones euromediterráneas, y para alcanzar el objetivo de la construcción de un espacio de paz, seguridad y prosperidad compartidas, resulta imprescindible profundizar el conocimiento que tenemos de las sociedades y de los actores sociales de los países árabes" (Saini, 2009: 2). Lamentablemente, y coincidiendo con las ideas Bensalah, "la nebulosa islamista, y la nebulosa de Al Qaida, han ido fundiéndose en el discurso mediático occidental acerca tanto del terrorismo internacional como de los actores sociales, a veces incluso partidos políticos, presentes en los países árabes" (Saini, 2009: 2). También intenta desmentir que el Islam sea una religión que fomenta la violencia; critica el uso de los medios de comunicación de masas del término "islamismo" como unión de islamismo y violencia; y remarca el olvido o la ignorancia del islamismo como proyecto político, social y de reivindicación de identidad. Todas estas ideas son las que intentaremos aplicar al caso de los medios de comunicación europeos y españoles.

\section{Metodología}

El objetivo principal de este artículo es analizar la relación entre los medios de comunicación y las religiones mayoritarias, o de notorio arraigo, que se practican en España y, en concreto, el Islam. Como objetivo subsidiario, se pretende abrir nuevas líneas de investigación y remarcar la importancia del asunto. Como decíamos en las primeras líneas, conocer las religiones que se practican en el país supone una mejor adecuación en el tratamiento de la información y los medios son transmisores de valores y estos, a su vez, socializadores de la audiencia.

El método utilizado consta de una investigación longitudinal y cualitativa sobre los principales autores que han estudiado y analizado el Islam en los medios de comunicación. El objetivo es conocer el Islam, las virtudes y errores de unir periodismo y religión en el caso concreto español, y promover nuevas líneas de investigación y la base de una posible ética periodística al hablar de religión.

\section{Desarrollo}

La diversidad cultural de los movimientos migratorios ha provocado que el sector de la comunicación haya tenido que adecuarse a la nueva realidad. La religión tiene un enorme potencial cultural y social. Puede establecer vínculos emocionales entre las personas y enlaza con los sistemas de valores seculares, ayudando a estructurar o reestructurar la convivencia social. También puede separar a las personas y tener efectos divisorios, cuando obstruye los procesos de integración social o promueve procesos de segregación (IOM, 2011). Más aún cuando los medios de comunicación no favorecen la correcta definición de conceptos, valores o ideas; y generalizan sus contenidos y noticias sobre religión o aspectos religiosos. Como explicábamos al principio, a la hora de abordar el fenómeno de la religión en los medios de comunicación, se puede destacar que la frontera entre la información y el espectáculo, o entre la noticia y el divertimento, es cada vez más difusa. 
La era de la globalización da pie, también, a la globalización del hecho religioso. Asistimos a la reaparición de la religión como noticia permanente en los diferentes medios de comunicación. En España, se consideran religiones de notorio arraigo las tres llamadas del Libro (Vela y Ballesteros, 2011: 362): Cristianismo, Judaísmo e Islam. Las tres son monoteístas y, aunque con diferencias de feligreses, están imbricadas en la sociedad desde hace siglos.

La comunidad musulmana, en el mundo, se compone, aproximadamente, de mil millones de personas. Dieciséis millones de musulmanes viven en Europa (Roy, 2012) y aproximadamente, dos millones en España. De estas cifras cabe señalar que el 70\% de las personas que se declaran musulmanes en España, son inmigrantes. Destaca el colectivo marroquí como grupo más numeroso, seguido, en este orden, por: argelinos, paquistaníes, iraníes, libaneses, sirios, egipcios, tunecinos, entre otras nacionalidades. El 30\% restante son españoles, que según Planet (2008), incluye a inmigrantes musulmanes que han obtenido la nacionalidad española y a españoles que se han convertido al culto islámico.

Para Losada (1995: 189-199), se pueden diferenciar cuatro corrientes del Islam en España y son las siguientes:

- Practicantes instalados: Son los inmigrantes de la primera generación que, en general, intentan evitar asimilarse a la sociedad de acogida.

- Musulmanes de segunda generación: Aquellas personas que no rechazan la cultura ni la religión de sus padres y se adaptan al modo de vida occidental, buscando una adecuada integración en la sociedad de acogida.

- Musulmanes islamistas: Con una percepción negativa en cuanto a la emigración de su país, debido al miedo a la asimilación y a la pérdida de su identidad religiosa.

- Musulmanes sociológicos: Con una referencia al Islam cultural más que al Islam de culto.

Así pues, la situación del culto islámico en el territorio español, como en casi todos los países europeos, está representado por la llegada de los inmigrantes procedentes de países musulmanes, y por la existencia de un marco jurídico e institucional que regula las cuestiones religiosas y la presencia del culto islámico (Planet, 2008: 1-32). De hecho, la libertad religiosa en España se consolidó después de la Ley de Libertad Religiosa de 28 de junio de 1967. Ésta fue el resultado de la apertura gradual de España y del proceso de renovación católica, surgida del Concilio Vaticano II. Abrió el camino para que otras confesiones no católicas, entre ellas la religión musulmana, creasen asociaciones o entidades religiosas (Tamayo, 2009).

A pesar de tener legislación, en España y en Europa, no se supo promover la diversidad religiosa en la sociedad. Esto permitió una influencia extranjera considerable en los ámbitos de financiación de los grupos radicales, construcción de espacios religiosos o la enseñanza del Islam. Todo ello ha perjudicado el proceso de integración del colectivo musulmán, autóctono e inmigrante, aunque deja margen a la producción de un Islam español que aboga por el respeto y la compatibilidad de los valores españoles y la concordia. 
Nos queremos centrar en el retrato del Islam en España y cómo éste puede afectar a las ideas que los españoles tienen sobre esta religión. Podemos adentrarnos de nuevo en los estudios de Bensalah (2006) y Saini (2009), porque sus ejemplos son igualmente válidos para el caso español. Muchos medios dan un mensaje reduccionista que, en la mayoría de los casos, deja un remanente negativo. Por ejemplo, Bravo (2009: 47-72) habla de "islamofobia y antimusulmanismo en España". Se centra en los trabajos de César Vidal, donde percibe "una imagen preestablecida e indiscutida del Islam como amenaza" (Bravo, 2009: 48).

Islam, Peters y White (2007: 281) argumentan que: "Hay toda una serie de polémicas recientes que resaltan esas tendencias. Entre ellas se incluyen la publicación en 2005 de las caricaturas del profeta Mahoma, los ataques y la violencia racistas en las calles de Francia y el Reino Unido, la ira provocada por el asesinato del cineasta Theo van Gogh en los Países Bajos, y el creciente sentimiento antiinmigración y antimusulmana en muchos países". Explican que los medios no han obrado de la forma más deseable: "La mayoría de los periódicos, emisoras de radio y televisión, y otros medios de comunicación, sin embargo, no han sabido asumir el reto de retratar la revolución social global. Lejos de suscitar el debate mediante la concienciación, de ayudar a combatir los prejuicios y de engendrar la comprensión intercomunitaria, un importante porcentaje de los principales medios de comunicación han contribuido a avivar los fuegos de la intolerancia y el racismo" (Islam, Peters y White, 2007: 283). Exponen que en Europa, "muchos periódicos siguen comprometidos con la concepción anticuada y obsoleta de un continente donde todavía se ve a inmigrantes y extranjeros como exóticos foráneos que han traído ideas y costumbres peligrosas" (Islam, Peters y White, 2007: 283).

Afortunadamente, los mismos autores declaran que hay excepciones positivas: "En toda Europa hay cada vez más reporteros que cuestionan los prejuicios. Las emisoras, especialmente las que tienen un mandato de servicio público, están centrándose cada vez más en las cuestiones relacionadas con las minorías en sus programas" (Islam, Peters y White, 2007: 283). Remarcamos, por ejemplo, el programa Islam hoy, de La 2 de Televisión Española. Presentado por Rian Ordóñez y dirigido por Mohamed Chakor, se ocupa de los temas de actualidad del colectivo islámico en España y de la recuperación del Islam histórico hispano (RTVE: 2012: Web). Igualmente, señalamos Córdoba Internacional TV que, desde enero de 2012, emite desde Madrid como "un canal temático con espacio para la cultura, la información, los niños, la religión o la ciencia, dirigido a todo el mundo hispanohablante y hecho desde una perspectiva islámica, que transciende los límites del ámbito religioso para dar a conocer a los musulmanes y al Islam en su dimensión social más amplia" (Córdoba Internacional TV, 2012: Web).

Ambos ejemplos españoles tienen su precedente en Al Jazeera, creada en 1996. Esta cadena árabe de información permanente vía satélite, emite desde el pequeño emirato de Qatar y se dio a conocer en 2001. Su propietario, el emir de Qatar, y el equipo profesional de la cadena, constituido por periodistas de diversas nacionalidades formados en el servicio árabe de la cadena británica BBC, resisten a las durísimas presiones de Estados Unidos y de otros países árabes, como Arabia Saudí y Egipto, 
para que se autocensuren (Valenzuela, 2012). Sin embargo y como decía Fátima Mernissi, Premio Príncipe de Asturias de las Letras, en 2003: "Al Jazeera e Internet son el germen de toda una revolución, la de la libertad de expresión en el universo árabe". Ya estaban ahí los signos precursores de la Primavera Árabe de 2011, pero casi nadie en el ensimismado mundo occidental quería verlos.

\section{Conclusiones}

Una vez analizada la situación y el tratamiento del Islam, en Europa y en España, 1legamos a la conclusión de que en los medios de comunicación hay una ausencia casi total del tratamiento religioso. Tratar el tema del Islam ha quedado sólo para informativos y casi siempre, con noticias reduccionistas que, a veces, pueden promover cierta islamofobia.

Hannerz (1996: 194) ya planteaba que: "El periodismo, a menudo y por razones prácticas, se ve forzado a no entrar en sutilezas. Sencillamente, no se puede hacer mucho con sólo tres columnas en el periódico o treinta segundo en la televisión. Y también tiene que ver, las más de las veces, el hecho de que el corresponsal esté en el país en conflicto. En este contexto, las personas, sobre todo la gente corriente, se nos muestran en una sola dimensión, al de victimas. Los han matado o los han herido, han perdido sus bienes y huyen del peligro".

Atendiendo a la cita de Hannerz, nos podríamos preguntar: ¿Cómo puede el periodista extenderse en explicaciones culturales o religiosas con el espacio o tiempo limitado que tiene para dar la información? También podríamos valorar que las nuevas generaciones no necesitan conocer una cultura para hablar de ella. Simplemente la sienten y la escriben, difundiéndola en la aldea global que se ha convertido el mundo. No tenemos nada más que pensar en la Primavera Árabe para entender esa nueva realidad.

Los medios de comunicación establecen unas fronteras que marcan la diferencia entre nosotros y ellos. Toda información se hace a partir de una perspectiva determinada. Dependiendo de las fronteras, se definen diferentes horizontes cognitivos y emotivos. La perspectiva con la que se construye el discurso informativo también instituye un conjunto de creencias y de afectos sobre la realidad social de la que se habla. El conjunto de creencias establecerá la frontera que nos separará de los otros (Rodrigo et al., 2009).

Nuestra visión del mundo, de la historia, de la cultura y, en definitiva, del ser humano, está íntimamente ligada a la visión que imponen los medios de comunicación. La ideología implícita se desprende de su propia estructura comunicativa: unidireccional y jerárquica. El control de los medios está en manos de empresas ligadas a grandes grupos económicos y de poder. El control de la información es económico. La información, por tanto, está sujeta a manipulación, y la selección de contenidos es uno de los elementos fundamentales en la ideología de los medios.

Es necesario cambiar esta corriente y atender a ejemplos como el programa Islam Hoy, de La 2 de Televisión Española, o la cadena Córdoba TV internacional, para buscar un periodismo religioso más ético y veraz, menos reduccionista. Sólo así podremos recordar la enorme responsabilidad de los profesionales y de los medios de comunicación. 


\section{Referencias bibliográficas}

BENSALAH, Mohamed (2006): "Islam y representaciones mediáticas". Revista CIDOB d'afers internacionals, no 73-74. Barcelona, Fundación CIDOB, pp. 69-83.

BRAVO, Fernando (2009): "Islamofobia y antimusulmanismo en España: el caso de César Vidal". Revista de Estudios Internacionales Mediterráneos, $\mathrm{n}^{\circ}$ 8. Madrid, Taller de Estudios Internacionales Mediterráneos de la Universidad Autónoma de Madrid, pp. 47-72.

CÓRDOBA INTERNACIONAL TV (2012): “Quiénes somos” en: http://www.cordobainternacional.com/index.php/quienes-somos.html [fecha de consulta: 15 de noviembre de 2012].

GARRETA, Jordi (2003): La integración sociocultural de las minorías étnicas. Barcelona, Anthropos.

HANNERZ, Ulf (1996): Conexiones transnacionales. Cultura, gente, lugares. Madrid, Cátedra.

IOM (2011): "Informe sobre las migraciones en el mundo 2011" en: http://publications.iom.int/bookstore/index.php?main_page=product_info\&products_id=754 [fecha de consulta: 16 de septiembre de 2012].

ISLAM, Shada, PETERS, Bettina y WHITE, Aidan (2007): "Iniciativa de Periodismo Ético. Medios de comunicación de calidad en defensa de la diversidad y el pluralismo". Cuadernos del Mediterráneo, $\mathrm{n}^{\circ}$ 8. Barcelona, Instituto Europeo del Mediterráneo, pp. 281-287.

LOSADA, Teresa (1995): "Inmigración musulmana: restos humanos, culturales y religiosos", en ABUMALHAM, Montserrat: Comunidades islámicas en Europa. Madrid, Trotta.

NECCO, Elisabetta (2010): Argumentos de bioética en el Islam: Aborto, planificación familiar e inseminación artificial. Madrid, CantArabia.

PAREKH, Bhikhu (2005): Repensando el multiculturalismo. Madrid, Istmo.

PLANET, Ana (2008): “Islam y emigración: elementos para un análisis y propuestas de gestión". Foro de Inmigración. Madrid, Centro de Estudios Políticos y Constitucionales, pp. 1-32.

RODRIGO, Miquel y MEDINA, Pilar (2009): "Los medios de comunicación en contextos interculturales". Sociedad y Discurso, no 16. Dinamarca, Universidad de Aalborg, pp. 21-39.

ROY, Olivier (2012): "Los nuevos islamistas". Foreign Policy, abril 2012. Madrid, Washingtonpost Newsweek Interactive.

RTVE (2012): "Islam hoy" en http://www.rtve.es/alacarta/videos/islam-hoy/ [fecha de consulta: 15 de noviembre de 2012].

SAINI, Valentina (2009): “Al Qaida y el islamismo: dos fenómenos distintos". RUTA: Revista Universitària de Treballs Acadèmics, $\mathrm{n}^{\circ}$ 2, 2009. Barcelona, Universidad Autónoma de Barcelona, pp. 1-17. 
SÁNCHEZ, Pilar (2012): "Londres 2012: Imaginemos entre culturas". Revista de Comunicación, $\mathrm{n}^{\circ}$ 25. Madrid, Wolters Kluwer España, pp. 21-23.

TAMAYO, Juan José (2009): Islam. Cultura, religión y política. Madrid, Trotta.

VALENZUELA, Javier (2012): Crónica del nuevo Oriente Próximo. Madrid, Los Libros de la Catarata.

VELA, Carmelina y BALLESTEROS, Carlos (2011): "La influencia de las creencias religiosas en el consumo. Una aproximación desde las tres religiones del Libro". Revista de las Facultades de Derecho y Ciencias Económicas y Empresariales. Madrid, ICADE, pp. 361-392.

\section{Pilar SÁNCHEZ GONZÁLEZ}

ESIC Business \& Marketing School

Profesora del Departamento de Comunicación

pilar.sanchez@esic.edu

\section{Graciela PADILLA CASTILLO}

Universidad Complutense de Madrid

Facultad de Ciencias de la Información. Departamento de Periodismo III

Profesora titular interina

gracielapadilla@ccinf.ucm.es 